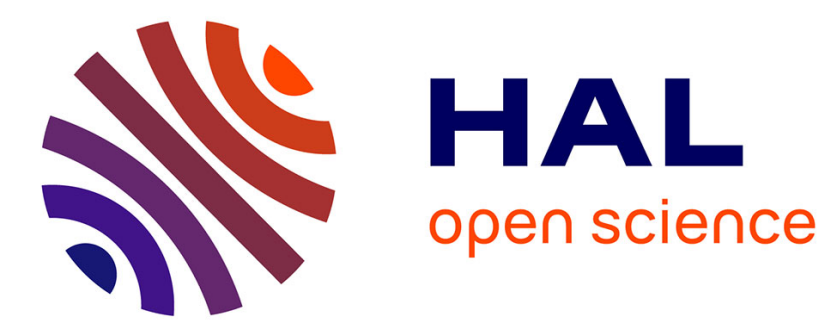

\title{
Supplementing Defect in Club Cell Secretory Protein Attenuates Airway Inflammation in COPD
}

Anne-Sophie Gamez, Delphine Gras, Aurélie Petit, Lucie Knabe, Nicolas

Molinari, Isabelle Vachier, Pascal Chanez, Arnaud Bourdin

\section{- To cite this version:}

Anne-Sophie Gamez, Delphine Gras, Aurélie Petit, Lucie Knabe, Nicolas Molinari, et al.. Supplementing Defect in Club Cell Secretory Protein Attenuates Airway Inflammation in COPD. Chest, 2015, 147 (6), pp.1467 - 1476. 10.1378/chest.14-1174 . hal-01756118

\section{HAL Id: hal-01756118 \\ https://hal.umontpellier.fr/hal-01756118}

Submitted on 2 Feb 2020

HAL is a multi-disciplinary open access archive for the deposit and dissemination of scientific research documents, whether they are published or not. The documents may come from teaching and research institutions in France or abroad, or from public or private research centers.
L'archive ouverte pluridisciplinaire HAL, est destinée au dépôt et à la diffusion de documents scientifiques de niveau recherche, publiés ou non, émanant des établissements d'enseignement et de recherche français ou étrangers, des laboratoires publics ou privés. 


\title{
Supplementing Defect in Club Cell Secretory Protein Attenuates Airway Inflammation in COPD
}

\author{
Anne Sophie Gamez, MD; Delphine Gras, PhD; Aurélie Petit, PhD; Lucie Knabe, MSc; Nicolas Molinari, PhD; \\ Isabelle Vachier, PhD; Pascal Chanez, MD, PhD; and Arnaud Bourdin, MD, PhD
}

BACKGROUND: Club cell secretory protein (CCSP) is a protective biomarker associated with annual decline in lung function. COPD progression results from an imbalance between injury and repair initially triggered by cigarette smoking.

OBJECTIVE: We investigated the effect of CCSP as a therapeutic strategy to restore the balance between injury and repair in COPD simultaneously, validating an ex vivo air-liquid interface (ALI) culture of human bronchial epithelial cells.

METHODS: Endobronchial biopsy specimens (EBBs) were obtained from 13 patients with COPD, eight smokers, and eight control subjects. Morphometric analysis of the initial EBBs was performed. ALI cultures derived from the same EBBs were exposed to cigarette smoke extract (CSE) with or without exogenous recombinant human CCSP (rhCCSP) supplementation. CCSP and IL-8 concentrations were assessed at steady state and after CSE exposure.

RESULTS: Morphometric analysis of the initial EBBs showed increased cell density but decreased immunostaining of CCSP + cells in EBBs of patients with COPD $(P=.03$ vs control subjects). At steady state, lower CCSP $(P=.04)$ and higher IL-8 levels $(P<.0001)$ were found in COPD ALI epithelium. Exogenous rhCCSP supplementation dampened CSE-induced IL-8-release in patients with COPD and returned to levels similar to those of smokers and control subjects $(P=.0001)$. A negative correlation was found between IL-8-release in ALI and CCSP + cell density in initial biopsy specimens $(P=.0073)$.

CONCLUSIONS: In vitro, rhCCSP exogenous supplementation can reverse CSE-induced IL-8 release in biopsy specimens from patients with COPD, indicating a potential use of this strategy in vivo.

\footnotetext{
Manuscript received May 15, 2014; revision accepted November 3, 2014; originally published Online First December 4, 2014.

ABBREVIATIONS: ALI $=$ air-liquid interface; $\mathrm{CCSP}=$ club cell secretory protein; CSE $=$ cigarette smoke extract; DAPI $=4$, 6 -diamidino-2phenylindole; $\mathrm{EBB}=$ endobronchial biopsy specimen; $\mathrm{LDH}=$ lactate dehydrogenase; $\mathrm{PBS}=$ phosphate-buffered saline; rhCCSP $=$ recombinant human club cell secretory protein

AfFiliations: From the Département de Pneumologie et Addictologie (Drs Gamez, Petit, Vachier, and Bourdin and Ms Knabe), Hôpital Arnaud de Villeneuve, CHU Montpellier; INSERM CNRS U1067 UMR7333 (Drs Gras and Chanez), Aix Marseille Université, Marseille; Département de l'Information Médicale (Dr Molinari), CHU Montpellier, Montpellier; UMR729 MISTEA (Dr Molinari), Montpellier SupAgro, Montpellier; Département des Maladies Respiratoires (Dr Chanez),
}

Hôpital Nord, AP-HM, Marseille; and INSERM U1046 (Ms Knabe and Dr Bourdin), Université Montpellier 1 et 2, Hôpital Arnaud de Villeneuve, CHU Montpellier, France.

FUNDING/SUPPORT: Master's degree support was provided to Dr Gamez by Association Pour Assistance Respiratoire à Domicile.

CORRESPONDENCE TO: Arnaud Bourdin, MD, PhD, Département de Pneumologie et Addictologie, Hôpital Arnaud de Villeneuve, 371 ave Doyen Gaston Giraud, CHU Montpellier, 34295 Montpellier Cedex 5, France; e-mail: a-bourdin@chu-montpellier.fr 
Imbalance between injury and repair is thought to play a critical role in COPD progression, as depicted by the presence of peribronchiolar fibrosis and hyperplasia of mucus-secreting epithelial cells. ${ }^{1}$ Interestingly, the club cell secretory protein (CCSP) polymorphisms have been involved in COPD pathogenesis, ${ }^{2}$ while serum CCSP level was found to be a major protective biomarker associated with annual decline of lung function. ${ }^{3}$ Club cells ${ }^{4}$ are thought to be a heterogeneous cellular population ${ }^{5}$ that plays a protective role in COPD thanks to its roles in proliferation (as a resident stem cell niche), detoxification, antiinflammation, and immunomodulation. ${ }^{6-9}$ Now a large body of evidence supports the notion that these cells play a critical role in epithelial regeneration and airway repair after injury..$^{10}$ Moreover, fewer CCSP-producing cells has been observed in COPD and other chronic airway diseases with a remodeling feature, such as asthma or post-transplant obliterative bronchiolitis. ${ }^{11-16}$

CCSP is a $10-\mathrm{kDa}$ protein. It is the most abundant protein found in BAL (2-4 mg/L) in humans. It is a small, globular, nonglycosylated, monodimeric protein. Its roles cover endogenous antiinflammatory properties through phospholipase A2 inhibition ${ }^{17}$ and subsequent decreased eicosanoid production. CCSP is also known to play an immunosuppressive role, predominantly against

\section{Materials and Methods}

\section{Subjects}

The study recruited 29 subjects (13 patients with COPD, eight smokers, and eight control subjects who had never smoked) at the Arnaud de Villeneuve Hospital, Montpellier, France, in 2010. COPD diagnosis was based upon evidence of nonreversible obstructive airflow $\mathrm{FEV}_{1} / \mathrm{FVC}<0.7, \mathrm{FEV}_{1}$ improvement after inhaling 200 to $400 \mu \mathrm{g}$ of albuterol $<12 \%$ and $200 \mathrm{~mL}$, and a smoking history of $>10$ pack-years; and without any evidence for alternative diagnosis according to the best standard of care (ie, no history of any other respiratory disease based on clinical examination or CT scan findings). Smoking status was recorded (active vs weaned). Smokers and healthy subjects had no airflow limitation. At the time of EBB collection, patients were at steady state and free of any exacerbation for at least 6 weeks. Bronchoscopy was performed when indicated by a chest physician, usually for peripheral-nodule exploration or other CT scan abnormalities. Bronchoscopy indication in control subjects was checked by the operator before enrollment and confirmed as follows: foreign body suspicion and/or removal $(n=5)$, traumatic pneumomediastinum $(n=2)$, and CT scan abnormality $(n=1$; corresponded to a peripheral nodule in a young patient without any respiratory disease, but discovered with an opacity at medical occupational visit on systematic chest radiograph [final diagnosis, hamartochondroma]). The study protocol was approved by the ethics committee of our institution (approval No. 2013-A00553-42), and all patients agreed to participate by reading and signing written informed consent forms. All measurements and experiments were performed in a blinded fashion.

\section{Endobronchial Biopsy Specimens}

All subjects underwent flexible bronchoscopy, and two to three biopsy specimens were collected from each patient by using alligator forceps
T-helper 2 cells. It is an antioxidant protein that contains a hydrophobic pocket for phospholipids and pollutants. Other properties may involve a direct interaction with

\section{FOR EDITORIAL COMMENT SEE PAGE 1447}

neutrophils that are potential, key cellular partners in COPD. ${ }^{18}$

Most of these findings rely on animal studies, in which club-cell biology is rather different from cell biology in humans. In mice, club cells are the predominant cell type in the airway from the trachea to the terminal bronchiole. ${ }^{8}$

Air-liquid interface (ALI) cultures of airway epithelium obtained from endobronchial biopsy specimens (EBBs) collected during bronchoscopy allow new insights into the dynamics and interactions of different epithelial cell phenotypes at steady state and after stimulation, in health and disease. ${ }^{19-22}$ We investigated if a CCSP defect is a hallmark of the airway epithelium in COPD and if it could be reproduced ex vivo in ALI cultures. We tried to restore the imbalance between injury and repair by using exogenous CCSP supplementation in ALI cultures obtained from control subjects, smokers, and patients with COPD, and from cultures exposed to cigarette smoke extracts (CSEs), with IL-8 release being the marker of injury.

(Olympus Corp) on a subsegmental bronchus of the left lower lobe, as previously described. ${ }^{23}$ Briefly, local anesthesia (lidocaine, $1 \%-5 \%$; maximum dose, $300 \mathrm{mg}$; AstraZeneca plc) was administered to the nasal and buccal cavity, followed by insertion of a fiber-optic bronchoscope (Olympus BF20; Olympus Corp) into the trachea through the nose.

\section{Measurements of Basement Membrane and Epithelial Thickness and of CCSP Positive Staining}

One biopsy specimen from each patient was fixed in neutral $4 \%$ formaldehyde buffer and embedded in paraffin. Four to six sections were apposed on a slide and stained with hematoxylin and eosin. Basement membrane and epithelial thicknesses were expressed as the average area-to-length ratio using Wilson's method, as previously described. ${ }^{24}$ All measurements were generated with a light microscope at $\times 400$ magnification (Olympus TH2; Olympus Corp) linked to a charged-couple device camera (Sony DXC950P; Sony Corp). Morphometric analyses were performed using dedicated software (Image); US National Institutes of Health). The pixel resolution was $0.02 \mu \mathrm{m}$.

CCSP staining was performed using CC protein human rabbit polyclonal antibody (Biovendor Inc). The stained area was expressed as a percentage of the total epithelial area. All nuclei were manually counted and cell density per $\mu \mathrm{m}^{2}$ of epithelial area was computed. All well-oriented (ie, perpendicular to the basement membrane with respect to a pseudostratified organization) fields per slice were measured. Results were expressed as a density of CCSP + cells (stained area of CCSP divided by total cell density).

To further characterize CCSP-expressing cells, dual staining was performed using, respectively, MUC5AC (Abcam plc) and tubulin IV (Sigma-Aldrich Co LLC) antibodies in four patients with COPD and 
four control subjects. 4',6-Diamidino-2-phenylindole (DAPI) (DAPI stain; Sigma-Aldrich Co LLC) was applied for nuclei counterstaining. Negative control subjects were assessed by applying the secondary antibody only (Alexa fluor 488 donkey anti-mouse IgG for MUC5AC and tubulin IV, and Alexa fluor 555 donkey anti-rabbit IgG for CCSP, respectively (both from InVitroGen Corp). Morphometric analysis was done at $\times 40$ magnification using dedicated software (Cell P; Olympus Corp). Total epithelial cell count was obtained by assessing the number of DAPI-counterstained nuclei, and different cell types were assessed. For each biopsy specimen, all adequate fields were analyzed eliciting computations from epithelial areas corresponding to 1 to $1.5 \mathrm{~mm}$ of the basement membrane length.

\section{Human Bronchial Epithelial Cell Primary Cultures Under ALI}

Primary human bronchial epithelial cells were obtained from remaining EBBs (usually two) and cultured under ALI conditions, as previously described by Gras et al. ${ }^{19}$ Cells were maintained in culture for 21 days to obtain a differentiated cell population with a mucociliary phenotype.

\section{Cigarette Smoke Extract}

Commercial cigarettes (Marlboro; Philip Morris USA Inc) were smoked by continuous suction in a chamber connected to a vacuum. Mainstream smoke was drawn through $30 \mathrm{~mL}$ of phosphate-buffered saline (PBS) that was prewarmed to $37^{\circ} \mathrm{C}$ by application of a vacuum to the vessel containing the PBS. Each cigarette was smoked for $8 \mathrm{~min}$, and three cigarettes were used per $30 \mathrm{~mL}$ of PBS to generate a CSE-PBS solution. This solution was adjusted to $\mathrm{pH} 7.4$ and the solution was sterilized through a $0.2-\mu \mathrm{m}$ filter. We obtained a $100 \%$ stock solution of CSE, diluted to $50 \%, 25 \%$, and $10 \%$ CSE solution. Solution equivalent to $0 \%$ CSE contained PBS only.

\section{Exposure of Bronchial Epithelial Cell Culture to CSE}

Time-course and dose-response slopes were acquired in seven control samples at time points $6,12,24$, and 48 h to select the most appropriate conditions. Mixed-effect models taking into account the repeated measurements showed no significant differences. Basically, CSE-induced IL-8 release was then visually chosen as being maximal without excessive cell mortality at $24 \mathrm{~h}$ of CSE exposure at a dilution of $50 \%$. Epithelial integrity and cell mortality were tested using morphologic appearance of the culture, and lactate dehydrogenase (LDH) release (enzyme-linked immunosorbent assay; Abcam plc) was assessed in the supernatant collected at $24 \mathrm{~h}$ in controlled conditions, and in CSE 50\%, and compared with Triton $1 \%$ (used as a reference for $100 \%$ mortality) in three samples.

\section{Exposure of Bronchial Epithelial Cells to Recombinant CCSP}

Inhibitory potentials of recombinant human CCSP (rhCCSP) (rhUteroglobin/SCGB1A1; R\&D Systems Inc) were tested at two different concentrations: 3 and $0.3 \mu \mathrm{g} / \mathrm{mL}$, which were the maximal and minimal concentrations found in BAL. rhCCSP was applied at the apical pole of culture cells in ALI with and without CSE.

\section{Measurement of IL-8 and CCSP Concentrations}

IL-8 and CCSP concentrations were assessed in the apical lavage of ALI cultures before and after CSE stimulation using enzyme-linked immunosorbent assay kits (Diaclone SAS and Biovendor Inc, respectively). Apical lavage was a brief rinse of the apical side of the cell layer in culture with $200 \mu \mathrm{L}$ of PBS gently reaspirated. Total RNA was purified from cell lysates (RNeasy; Qiagen NV), and cDNA was synthesized (Readyto-Go RT-PCR beads; General Electric Co). Human CCSP gene expression was determined by quantitative reverse transcriptase-polymerase chain reaction (LightCycler480; F. Hoffmann-La Roche Ltd) using SybrGreen and specific primers (Eurofins MWG Operon Inc), and using glyceraldehyde 3-phosphate dehydrogenase as an internal control.

\section{Statistical Analysis}

Continuous variables were expressed as mean and SD when normally distributed and then compared using analysis of variance; in other cases, median and interquartile ranges were considered and comparisons done using a nonparametric test. A mixed-effect model was built to test for repeated measures when applicable. A nonlinear regression was tested for correlations between initial biopsy-specimen data derived from morphometric analysis and data generated upon ALI cultures. As there were no data available in the literature, the study size was based upon our preliminary results.

\section{Results}

\section{Subject Characteristics}

Bronchial biopsy specimens from 13 patients with COPD, eight smokers, and eight healthy subjects successfully grew in ALI culture and were considered for analysis. Clinical characteristics of the subjects are reported in Table 1. Most patients with COPD had mild airflow obstruction, were men, and had been weaned from smoking for more than 1 year. Cumulative smoking history was similar in patients with COPD and smokers. Patients with COPD were taking more medications than the smokers, including inhaled corticosteroids and long-acting bronchodilators.

\section{Morphometric Analysis and CCSP Staining in Proximal Airways}

Morphometric analysis showed a significant increase in epithelial cell density in COPD as compared with smokers and control subjects (Table 2). While negative control cultures (secondary antibody only) showed no detectable staining, we found a significant decrease in
CCSP-expressing cell density in the airway epithelium obtained from patients with COPD $(P=.030$ between control subjects and COPD) (Table 2). Representative pictures of CCSP immunostaining are given in Figures $1 \mathrm{~A}$ and $1 \mathrm{~B}$. CCSP-expressing cells usually presented as undistinguishable epithelial cells, nonciliated and nonmucous, with staining predominant at the apical side next to the lumen. Representative pictures of dual staining assessed for CCSP-MUC5AC and CCSP-tubulin IV are presented in Figure 1C. Basically, only few cells exhibited dual staining for both MUC5AC and CCSP, and this never occurred with tubulin IV. Similar levels of those double-positive CCSP-MUC5AC cells were seen in cultures from patients with COPD and control subjects. More MUC5AC- and fewer CCSP-expressing cells were observed in cultures from patients with COPD (ratio CCSP/MUC5AC-expressing cells, $0.2 \pm 0.1$ vs $0.8 \pm 0.8 ; P=.05$ ).

\section{CCSP in Upper Lavage of Cell Cultures}

CCSP concentrations were significantly lower in the apical lavage of ALI cultures from patients with COPD 
TABLE 1 ] Demographic Description of the Subjects

\begin{tabular}{|c|c|c|c|c|}
\hline Characteristics & $\operatorname{COPD}(n=13)$ & Smokers $(n=8)$ & Control Subjects $(n=8)$ & $P$ Value \\
\hline Age, mean $\pm S D, y$ & $60.6 \pm 14.2$ & $47.7 \pm 17.4$ & $44.1 \pm 22.9$ & .1422 \\
\hline Sex, \% male & 92.3 & 62.5 & 50 & .0660 \\
\hline Cumulative smoking, mean $\pm S D$, pack-y & $37.3 \pm 17.7$ & $40.0 \pm 16.8$ & NA & $.7880^{\mathrm{a}}$ \\
\hline $\mathrm{FEV}_{1} / \mathrm{FVC}$, mean $\pm \mathrm{SD}$ & $0.547 \pm 0.135$ & $0.805 \pm 0.076$ & $0.782 \pm 0.058$ & $<.0001$ \\
\hline $\mathrm{FEV}_{1}$, mean $\pm \mathrm{SD}, \%$ & $59.8 \pm 25.7$ & $91.1 \pm 10.4$ & $106.3 \pm 18.4$ & .0004 \\
\hline GOLD 2011 status, \% I-II & 61 & NA & NA & NA \\
\hline Smoking status, $\%$ weaned $>1$ y & 69.3 & 0 & NA & NA \\
\hline Treatments, \% & & & & NA \\
\hline ICS & 39 & 0 & 0 & \\
\hline LABA & 54 & 0 & 0 & \\
\hline LAMA & 39 & 0 & 0 & \\
\hline Otherb & 23 & 25 & 0 & \\
\hline
\end{tabular}

GOLD = Global Initiative for Chronic Obstructive Lung Disease; ICS = inhaled corticosteroid; LABA = long-acting $\beta$-adrenoceptor agonist; LAMA = longacting muscarinic antagonist; NA = not applicable.

aDifference between patients with COPD and smokers.

bOther treatments included statins and angiotensin-converting enzyme inhibitors, respectively, in three and two patients with COPD and statins in two smokers.

when compared with that of control subjects $(P=.040)$. CSE was added at $50 \%$ for $24 \mathrm{~h}$ and had no significant effect on CCSP release (Fig 2A). CCSP mRNA expression was not significantly different between groups (Fig 2B). Epithelial integrity and viability were unaffected by CSE 50\%, as direct observation of the cultures showed persistent cilia beating and mucus secretion; LDH concentrations remained similar to control conditions and lower than cultures exposed to Triton 1\% (Fig 2C).

\section{rhCCSP Modulates CSE-Induced IL-8 Release}

Basal levels of IL-8 were significantly increased at steady state and after CSE exposure in ALI cultures from patients with COPD $(P=.048)$ (Fig 3A). Exogenous supplementation with rhCCSP dramatically reduced CSE-induced IL-8 release in patients with COPD (mixed-effect model, overall $P$ value in COPD $=.0005$; combined group and rhCCSP effect in COPD, $P=.0001$ for both rhCCSP concentrations of 300 and 3,000 ng/mL). There was no significant effect in other groups and conditions (Fig 3B). At the basolateral side, IL-8 con- centrations were similar in upper lavages ( $t$ test $P=.74$ for $\mathrm{n}=11$; as some data were missing, only upper lavages were analyzed).

\section{Correlation Between CCSP + Cells and Basal IL-8 Levels}

Exploratory correlations between initial biopsy and culture finding were tested. The number of CCSP-expressing cells in the initial EBB was significantly negatively correlated with the initial IL-8 concentration in the apical ALI culture lavage following an exponential distribution $\left(r^{2}=0.7249, P=.0073\right)$ (Fig 4).

\section{Discussion}

In the present study, we first demonstrated fewer CCSP + cells associated with an increased epithelial density in the proximal airways of patients with COPD. For the first time to our knowledge, decreased CCSP production contrasted with increased IL-8 production was reproduced in the ex vivo model of ALI culture of bronchial epithelium, mimicking the imbalance between

TABLE 2 ] Morphometric Analysis of the Initial Endobronchial Biopsy Specimens

\begin{tabular}{l|c|c|c|c}
\hline Criteria & COPD $(n=13)$ & Smokers $(n=8)$ & Control Subjects $(n=8)$ & $P$ Value \\
\hline Basement membrane thickness, $\mu \mathrm{m}$ & $8.8 \pm 0.9$ & $12.0 \pm 2.1$ & $10.1 \pm 4.3$ & .389 \\
Epithelial thickness, $\mu \mathrm{m}$ & $55.8 \pm 22.6$ & $42.4 \pm 7.1$ & $41.4 \pm 8.3$ \\
Epithelial cell density (No. of cells/mm BM) & $0.640 \pm 0.403$ & $0.337 \pm 0.106$ & $0.305 \pm 0.055$ \\
CCSP+ cell density (\% stained area/cell density) & $10.8 \pm 9.9$ & $35.9 \pm 59.2$ & $51.6 \pm 33.4$ \\
\hline \hline
\end{tabular}




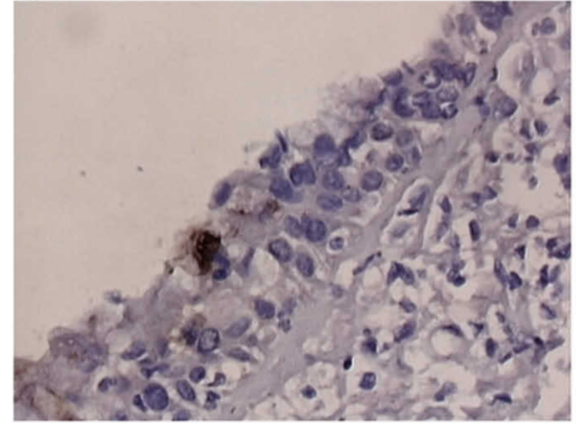

B

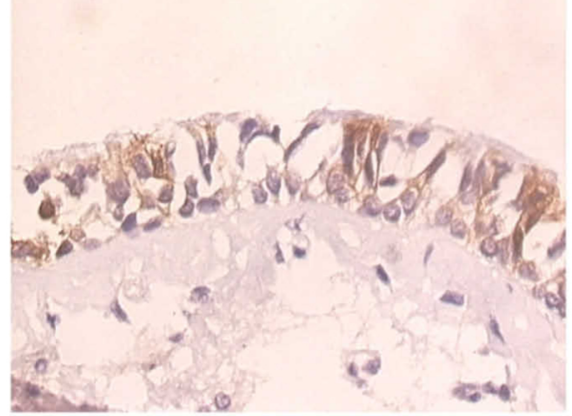

Negative control
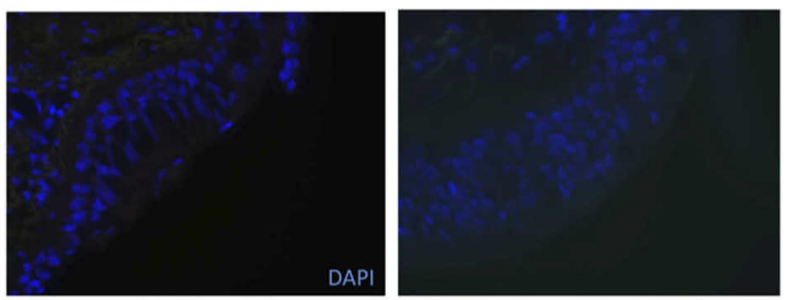

MUC5AC - CCSP
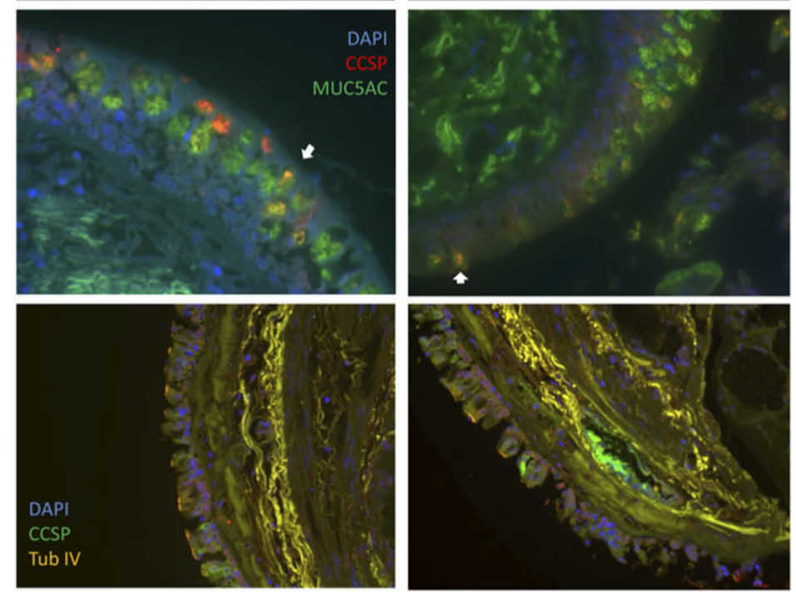

Figure 1 - Representative pictures of CCSP staining in paraffin-embedded biopsy specimens (CCSP stain, original magnification $\times 400$ ). A, Staining of a biopsy specimen from a patient with COPD. B. Only few apical CCSP + stained areas are seen contrasting with a wider repartition and intensity in control subjects. C, Representative pictures of dual staining for CCSP-MUC5AC and CCSP-tubulin IV in specimens from control subjects and patients with COPD and their respective control cultures (secondary antibodies only) observed in paraffin-embedded, initial bronchial biopsy specimens. White arrows indicate dual-stained cells. CCSP $=$ club cell secretory protein; DAPI =4;6-diamidino-2-phenylindole.

inflammation and repair that are the hallmarks of COPD. Second, addition of rhCCSP in ALI cultures, stimulated by CSE, showed a dramatic decrease of apical IL-8 released in patients with COPD. Finally, density of CCSPexpressing cells in the initial EBB negatively correlated with basal IL-8 release assessed during ALI culture.

CCSP-related cells were reported in the proximal airways in the present study and were found in our reconstituted model. These cells were initially described in the distal airways, but they have been found by other authors in the whole bronchial tree..$^{14,25}$ The present findings confirmed previous reports ${ }^{13,14,25}$ showing fewer CCSP + cells in various diseases, including COPD and bronchiolitis obliterans syndrome, at the distal level. Of note, CCSPexpressing cells in the proximal airways may also express MUC5AC but not tubulin IV, suggesting a potential of CCSP-expressing cells to differentiate into goblet cells. In that case, double-stained cells may represent cells following this process and expressing both markers transiently. 5,20

The decrease in CCSP release from the reconstituted epithelium in ALI was consistent with previous reports showing a decreased level in BAL and sputum fluid supernatants. ${ }^{11,26}$ Some reports related CCSP polymor- phisms to COPD clinical and functional characteristics. CCSP was proposed as a potential biomarker that may protect against accelerated $\mathrm{FEV}_{1}$ decline in COPD.,3

This came with the development of the pneumoprotein serum levels increase as pneumoproteins leak from the airway due to various injuries. ${ }^{27}$

The defect in CCSP cells and the low level observed in the present study suggest a crucial role for CCSP as a marker of structural changes in the epithelium in COPD. CCSP can orchestrate regeneration/reparation at the site of epithelial injury, especially in distal airways. We extended this role to the whole bronchial tree. It can be an important marker for COPD and a potential agent participating in the healing process.

ALI cultures are widely used as interesting humanderived cellular models to test new hypotheses and treatments in chronic airway diseases. We reported that airway epithelial cell phenotype was sustained ex vivo in severe asthma. ${ }^{19}$ These findings led us to use this model in COPD and investigate new mechanisms associated with this devastating disease.

Using this ex vivo model, we report an exaggerated release of the inflammatory mediator IL-8 and a 


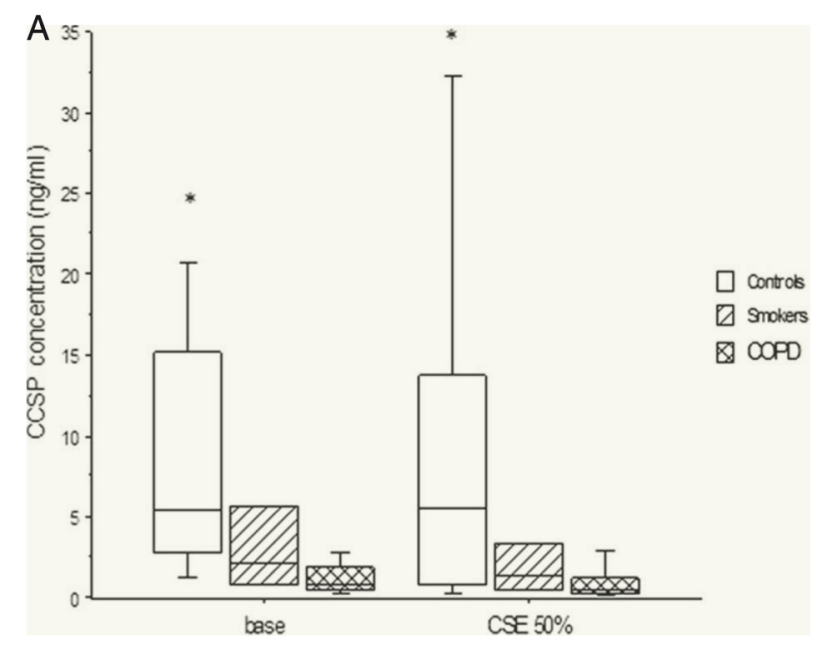

B

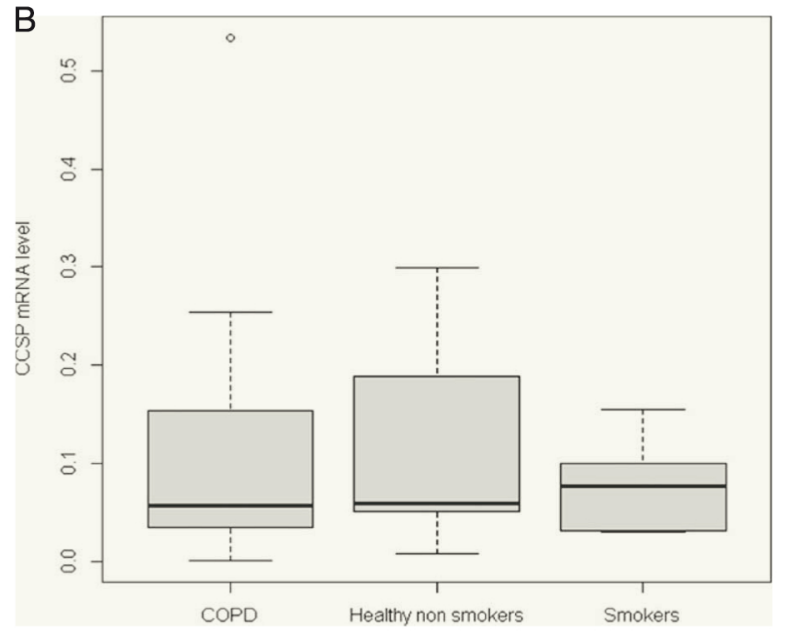

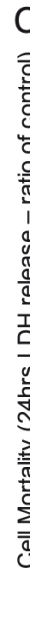

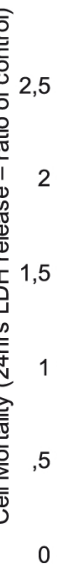

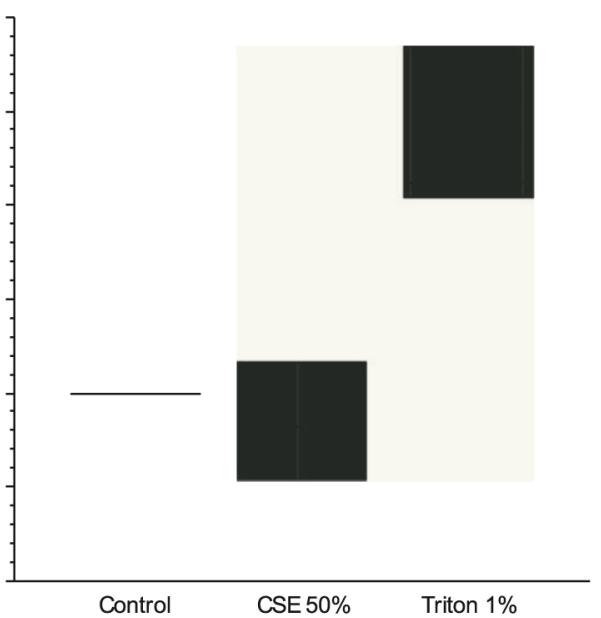

Figure 2 - A, CCSP levels in air-liquid interface (ALI) apical lavage (between-group $\mathrm{P}=.04$ at baseline; CSE had no significant effect [mixedeffect model $\mathrm{P}=.84$ for interaction between condition and groups]). Boxplots display median and interquartile ranges, while error bars represent $95 \%$ CIs. B, CCSP $m R N A$ values at baseline (between-group $\mathrm{P}=.72$ ). Boxplots display median and interquartile ranges, while whisker bars represent 1 SD above the mean. Outliers are plotted as individual points. $C, L D H$ release at $24 \mathrm{~h}$ in the ALI supernatant from cultures unexposed (control), exposed to CSE 50\%, and compared with Triton 1\%. CSE = cigarette smoke extract; $L D H=$ lactate dehydrogenase; $m R N A=$ messenger RNA. See Figure 1 legend for expansion of other abbreviation. decreased CCSP release in COPD. We used rhCCSP at different doses that reproduced the range of in vivo BAL concentrations. Our results seemed unaffected by the dose. We carefully checked the baseline spontaneous CCSP release levels, and what we observed was not related to CSE.

Those findings fit previous data ${ }^{28,29}$ obtained using $\mathrm{BAL}^{30,31}$ or induced sputum analysis. ${ }^{11,32}$ They can be combined with the numerous studies showing neutrophilic infiltration in biopsy specimens, as IL-8 is a well-known, potent, neutrophil chemoattractant factor.

Our data support the persistence or "memory" of a proinflammatory phenotype at the epithelial level in COPD despite the different steps of the culturing process and the duration of the procedure to restore a fully differentiated bronchial epithelium. Those findings indicate that abnormal epithelium is a constant characteristic of the bronchi in COPD and may be a target for a real diseasemodifying drug. Critical views on epigenetic transformation of the airway epithelium in COPD are required to better understand whether it can be reversed or not. ${ }^{33-36}$

Various microorganisms and active smoking are known proinflammatory triggers of the epithelium in COPD. Of note, none of the patients with COPD were still active smokers, and we performed biopsy procedures at a long distance from a potential infectious, related episode. The smokers included were quite heavy smokers (similar to COPD), so they were considered as not susceptible to COPD development. The cell cultures of the smoker group behaved more like control subjects than patients with COPD, which suggests that our findings are more related to the disease than the cigarette smoke only. Moreover, IL-8 release assessed in the apical lavage of ALI cultures at steady state was similar in smokers and control subjects. This was not the case for CCSP release, where a trend toward a decrease was also seen in smokers (the role of ongoing active smoking could not be properly addressed in our study). Potentially, most CCSP production may take place lower in the airways in vivo and the proximal assessment presently evaluated may not reflect the whole organ. Interestingly, we found no difference in messenger RNA expression between groups, suggesting posttranscriptional regulations, including the possibility of a nonsecreted form of the protein. The ability of rhCCSP supplementation to significantly reduced CSE-induced IL- 8 release in patients with COPD led us to consider its use as a therapeutic agent. 


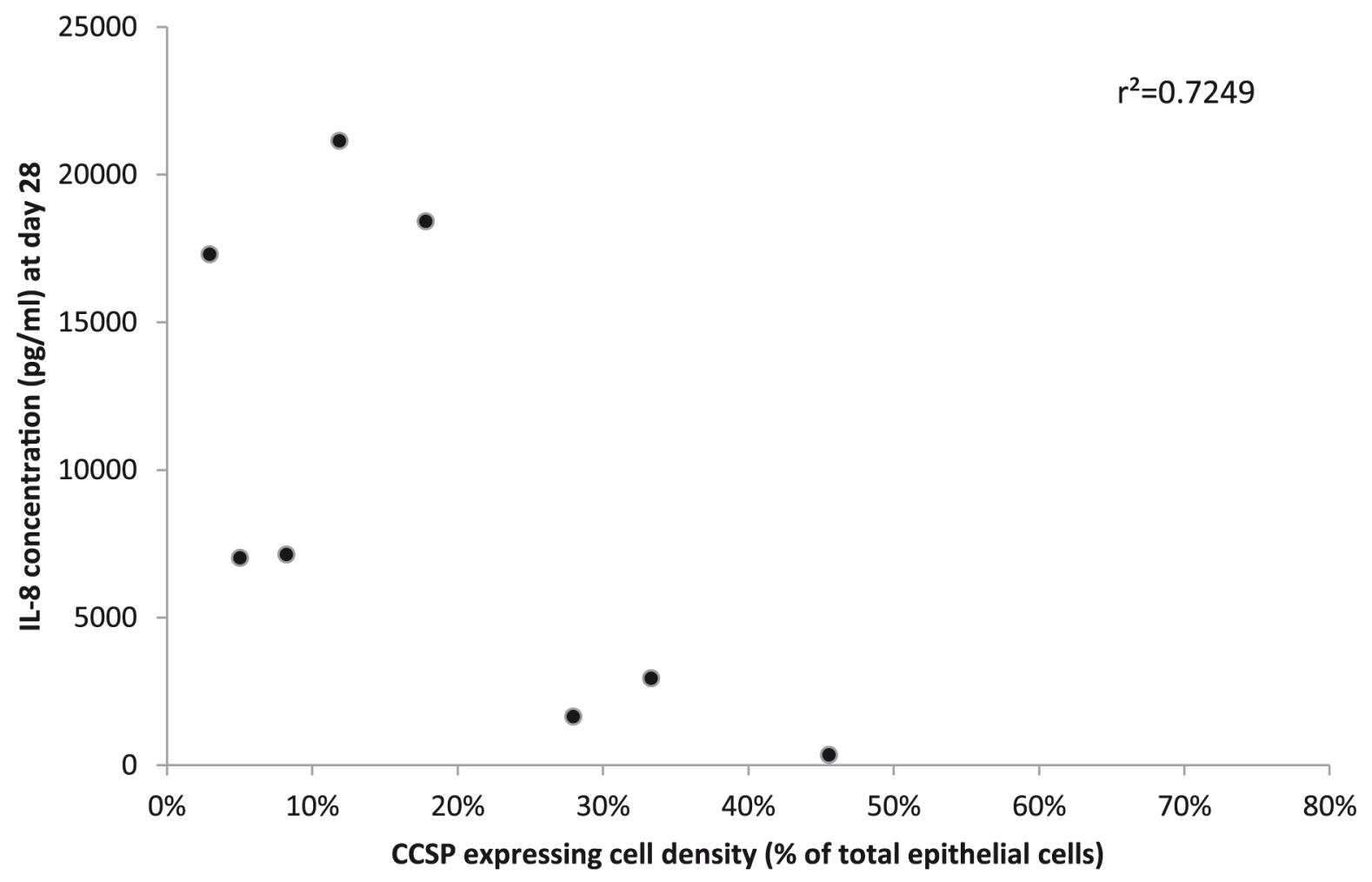

Figure 4 - Correlation between density of CCSP-expressing cells in the initial biopsy specimens and IL-8 levels in ALI culture at d 28 (P $=.0073)$. See Figure 1 and 2 legends for expansion of abbreviations.

We observed a correlation between data obtained from the initial biopsy specimens and from the ALI culture. This also validates the consistency of our ex vivo model. This negative relationship between CCSP-expressing cells and IL-8 is a potential validation of their biologic link despite the absence of causative link. It also supports the hypothesis that a sustained imbalance between injury and repair is involved in COPD pathobiology, even at baseline, as this relationship is negative. A tight link between IL-8/neutrophils and CCSP has been already suggested in previous reports. ${ }^{6,8,11,14,18}$ The exponential shape of the relationship was not observed before. It suggests the existence of a still-unknown intermediate hub.

The absence of investigation of the mechanisms responsible for the defect in CCSP or for the inhibition of CSE-induced IL- 8 release by rhCSSP use is a limitation of the present study. Regarding IL-8 inhibition, nuclear factor- $\kappa \mathrm{B}$ and mitogen-activated protein kinase pathways are obvious candidate targets for rhCCSP, although the lack of sufficient samples and remaining material precluded these investigations in the present study. Causes of decreased numbers of CCSP + cells and CCSP epithelial release may involve susceptibility pathways worth understanding.

Whether CCSP acts directly or indirectly at the cell level, through an unknown cell receptor or by binding surrounding toxicants and then limiting their deleterious cell effects, is somewhat important, but the resulting less-pronounced inflammatory signal is potentially more important clinically. Recent evidence of nuclear factor-kB and ERK1/2 downexpression under CCSP supplementation are providing meaningful insight into cell changes offered by CCSP, even though this does not really better address the question presently raised..$^{37}$

Overall, this study is an original contribution to a better understanding of COPD, with an emphasis on a defect in a physiologic host-defense process. These findings need confirmatory data but raise hope for a more mechanistic attempt, using exogenous CCSP, to interfere with the natural history of COPD. 


\section{Acknowledgments}

Author contributions: A. B. had full access to all of the data in the study and takes responsibility for the integrity of the data and the accuracy of the data analysis. A. S. G. served as principal author. A. S. G. and I. V. contributed to the study concept; P. C. and A. B. contributed to the study design; A. S. G., D. G., A. P., L. K., P. C., and A. B. contributed to laboratory investigations; N. M. and A. B. contributed to data analysis and interpretation; A. S. G., D. G., A. P., N. M., I. V., and P. C. contributed to manuscript preparation; and L. K. and A. B. contributed to review of the manuscript.

Financial/nonfinancial disclosures: The authors have reported to CHEST the following conflicts of interest: Dr Chanez has provided consultancy services for Almirall SA, Boehringer Ingelheim $\mathrm{GmbH}$, Centocor Biotech Inc, GlaxoSmithKline plc, Merck \& Co Inc, AstraZeneca plc, Novartis AG, Teva Pharmaceutical Industries Inc, Chiesi Pharmaceuticals Inc, and Schering Plough Corp; has served on advisory boards for Almirall SA, Boehringer Ingelheim $\mathrm{GmbH}$, Centocor Biotech Inc, GlaxoSmithKline plc, AstraZeneca plc, Novartis AG, Teva Pharmaceutical Industries Inc, Chiesi Pharmaceuticals Inc, Schering Plough Corp, and Merck \& Co Inc; has received lecture fees from Almirall SA, Boehringer Ingelheim $\mathrm{GmbH}$, Centocor Biotech Inc, GlaxoSmithKline plc, AstraZeneca plc, Novartis AG, Teva Pharmaceutical Industries Inc, Chiesi Pharmaceuticals Inc, Schering Plough Corp, and Merck \& Co Inc; and has received industrysponsored grants from Almirall SA, Boston Scientific Corp, Boehringer Ingelheim $\mathrm{GmbH}$, Centocor Biotech Inc, GlaxoSmithKline plc, AstraZeneca plc, Novartis AG, Teva Pharmaceutical Industries Inc, Chiesi Pharmaceuticals Inc, and Schering Plough Corp. Dr Bourdin has served on advisory boards for Almirall SA, Boehringer Ingelheim $\mathrm{GmbH}$, GlaxoSmithKline plc, AstraZeneca plc, and Novartis AG and has received lecture fees from Boehringer Ingelheim $\mathrm{GmbH}$, GlaxoSmithKline plc, AstraZeneca plc, Novartis AG, and Chiesi Pharmaceuticals Inc. Drs Gamez, Gras, Petit, Molinari, and Vachier and Ms Knabe have reported to CHEST that no potential conflicts of interest exist with any companies/organizations whose products or services may be discussed in this article.

Role of sponsors: The sponsor had no role in the design of the study, the collection and analysis of the data, or the preparation of the manuscript.

Other contributions: The authors would like to thank the Association pour l'Assistance Respiratoire á Domicile for their support.

\section{References}

1. Hogg JC, Chu F, Utokaparch S, et al. The nature of small-airway obstruction in chronic obstructive pulmonary disease. N Engl J Med. 2004;350(26):2645-2653.

2. Kim DK, Cho MH, Hersh CP, et al; ECLIPSE, ICGN, and COPDGene
Investigators. Genome-wide association analysis of blood biomarkers in chronic obstructive pulmonary disease. Am J Respir Crit Care Med. 2012;186(12): 1238-1247.

3. Vestbo J, Edwards LD, Scanlon PD, et al; ECLIPSE Investigators. Changes in forced expiratory volume in 1 second over time in COPD. N Engl J Med. 2011; 365(13):1184-1192.

4. Winkelmann A, Noack T. The Clara cell: a "Third Reich eponym"? Eur Respir J. 2010;36(4):722-727.

5. Randell SH. Airway epithelial stem cells and the pathophysiology of chronic obstructive pulmonary disease. Proc Am Thorac Soc. 2006;3(8):718-725.

6. Hayashida S, Harrod KS, Whitsett JA. Regulation and function of CCSP during pulmonary Pseudomonas aeruginosa infection in vivo. Am J Physiol Lung Cell Mol Physiol. 2000;279(3):L452-L459.

7. Pilon AL. Rationale for the development of recombinant human $\mathrm{CC} 10$ as a therapeutic for inflammatory and fibrotic disease. Ann N Y Acad Sci. 2000;923: 280-299.

8. Singh G, Katyal SL. Clara cell proteins. Ann N Y Acad Sci. 2000;923:43-58.

9. Wang SZ, Rosenberger CL, Bao YX, Stark JM, Harrod KS. Clara cell secretory protein modulates lung inflammatory and immune responses to respiratory syncytial virus infection. J Immunol. 2003;171(2):1051-1060.

10. Perl AK, Riethmacher D, Whitsett JA. Conditional depletion of airway progenitor cells induces peribronchiolar fibrosis. Am J Respir Crit Care Med. 2011;183(4): 511-521.

11. Bourdin A, Kotsimbos T, Nguyen K, et al. Non-invasive assessment of small airway remodelling in smokers. COPD. 2010;7(2):102-110.

12. Bourdin A, Mifsud NA, Chanez B, Chanez P, Snell G, Kotsimbos TC. Clara cells and injury post lung transplantation: an evolving story. Am J Transplant. 2013;13(5):1370

13. Bourdin A, Mifsud NA, Chanez B, et al. Donor Clara cell secretory protein polymorphism is a risk factor for bronchiolitis obliterans syndrome after lung transplantation. Transplantation. 2012;94(6):652-658.

14. Pilette C, Godding V, Kiss R, et al. Reduced epithelial expression of secretory component in small airways correlates with airflow obstruction in chronic obstructive pulmonary disease. Am J Respir Crit Care Med. 2001;163(1):185-194.

15. Shijubo N, Itoh Y, Shigehara K, et al. Association of Clara cell 10-kDa protein, spontaneous regression and sarcoidosis. Eur Respir J. 2000;16(3):414-419.

16. Shijubo N, Itoh $\mathrm{Y}$, Yamaguchi $\mathrm{T}$, et al. Clara cell protein-positive epithelial cells are reduced in small airways of asthmatics. Am J Respir Crit Care Med. 1999;160(3):930-933.

17. Shiyu S, Zhiyu L, Mao Y, et al. Polydatin up-regulates Clara cell secretory protein to suppress phospholipase A2 of lung induced by LPS in vivo and in vitro. BMC Cell Biol. 2011;12:31.

18. Katavolos P, Ackerley CA, Clark ME, Bienzle D. Clara cell secretory protein increases phagocytic and decreases oxidative activity of neutrophils. Vet Immunol Immunopathol. 2011;139(1):1-9.

19. Gras D, Bourdin A, Vachier I, et al. An ex vivo model of severe asthma using reconstituted human bronchial epithelium. J Allergy Clin Immunol. 2012;129(5): 1259-1266e1.

20. Gras D, Chanez P, Vachier I, Petit A, Bourdin A. Bronchial epithelium as a target for innovative treatments in asthma. Pharmacol Ther. 2013;140(3): 290-305.

21. Warner SM, Hackett TL, Shaheen F, et al. Transcription factor p63 regulates key genes and wound repair in human airway epithelial basal cells. Am J Respir Cell Mol Biol. 2013;49(6):978-988.

22. Xiao C, Puddicombe SM, Field S, et al Defective epithelial barrier function in asthma. J Allergy Clin Immunol. 2011; 128(3):549-556.

23. Jeffery P, Holgate S, Wenzel S; Endobronchial Biopsy Workshop. Methods for the assessment of endobronchial biopsies in clinical research: application to studies of pathogenesis and the effects of treatment. Am J Respir Crit Care Med. 2003; 168(6 pt 2):S1-S17.

24. Wilson JW, Li X. The measurement of reticular basement membrane and submucosal collagen in the asthmatic airway. Clin Exp Allergy. 1997;27(4):363-371.

25. Boers JE, Ambergen AW, Thunnissen FB. Number and proliferation of Clara cells in normal human airway epithelium. Am J Respir Crit Care Med. 1999; 159(5 pt 1):1585-1591.

26. Broeckaert F, Clippe A, Knoops B, Hermans C, Bernard A. Clara cell secretory protein (CC16): features as a peripheral lung biomarker. Ann N Y Acad Sci. 2000;923:68-77.

27. Hermans C, Bernard A. Lung epithelium specific proteins: characteristics and potential applications as markers. Am J Respir Crit Care Med. 1999;159(2): 646-678.

28. Heijink IH, de Bruin HG, van den Berge $\mathrm{M}$, et al. Role of aberrant WNT signalling in the airway epithelial response to cigarette smoke in chronic obstructive pulmonary disease. Thorax. 2013;68(8): 709-716.

29. Starrett W, Blake DJ. Sulforaphane inhibits de novo synthesis of IL-8 and MCP-1 in human epithelial cells generated by cigarette smoke extract. J Immunotoxicol. 2011;8(2):150-158.

30. Cheng SL, Wang HC, Yu CJ, Yang PC. Increased expression of placenta growth factor in COPD. Thorax. 2008;63(6): 500-506.

31. Drost EM, Skwarski KM, Sauleda J, et al. Oxidative stress and airway inflammation in severe exacerbations of COPD. Thorax. 2005;60(4):293-300. 
32. Vachier I, Vignola AM, Chiappara G, et al. Inflammatory features of nasal mucosa in smokers with and without COPD. Thorax. 2004;59(4):303-307.

33. Barnes PJ. Targeting the epigenome in the treatment of asthma and chronic obstructive pulmonary disease. Proc Am Thorac Soc. 2009;6(8): 693-696.
34. Barnes PJ. New anti-inflammatory targets for chronic obstructive pulmonary disease. Nat Rev Drug Discov. 2013;12(7):543-559.

35. Wan ES, Qiu W, Baccarelli A, et al. Systemic steroid exposure is associated with differential methylation in chronic obstructive pulmonary disease. Am J Respir Crit Care Med. 2012;186(12):1248-1255.
36. Yang IV, Schwartz DA. Epigenetic control of gene expression in the lung. Am J Respir Crit Care Med. 2011;183(10):1295-1301.

37. Tokita E, Tanabe T, Asano K, Suzaki H, Rubin BK. Club cell 10-kDa protein attenuates airway mucus hypersecretion and inflammation. Eur Respir J. 2014;44(4):1002-1010. 